\title{
Study on creep behavior of Grade 91 steel at $838 \mathrm{~K}$
}

\author{
Facai Rena ${ }^{a}$ Xiaoying Tang ${ }^{b}$ \\ Shanghai Institute of Special Equipment Inspection and Technical Research, \\ No. 915 Jinshajiang Road, Shanghai, 200062, PR China \\ acaifaren@163.com, bytang@ssei.cn
}

Keywords: Creep behavior, Grade 91 steel, Minimum creep rate, Rupture time.

\begin{abstract}
Creep deformation behavior of Grade 91 steel used for steam cooler has been studied. Creep tests were carried out using uniaxial creep specimens machined from the normalized and tempered plate at $838 \mathrm{~K}$ with stresses of $200,215,225$ and $250 \mathrm{MPa}$. The creep data were analyzed in terms of Norton's power law, Monk man-Grant (MG) relation and modified Monk man-Grant (MMG) relation. The results show that the Grade 91 steel obeys MG and MMG relationships.
\end{abstract}

\section{Introduction}

The Grade 91 steels have been considered as superior material due to lower coefficient of thermal expansion and high thermal conductivity and resistance to thermal fatigue, in comparison with creep resistant austenitic steels [1]. Due to the good creep strength, Grade 91 steel is used for the steam and gas turbines or boiler at elevated temperatures. It contains alloying elements like $\mathrm{Nb}$ and $\mathrm{V}$, forming fine and stable carbides and/or carbonitrides, which can improve its excellent high temperature creep strength [2]. The elements addition can improve the creep strength by disrupting the movement of dislocations, delaying the plastic deformation by inhibiting grain boundary sliding and retaining finer grains during austenitization [3].

The creep deformation behavior of Grade91 steel has been investigated by many researchers in the past years. Chen et al. [4] addressed the overestimation of the time-temperature-parameter method on the allowable creep strength of 9-12\% Cr heat-resistant steels. Anderson et al. [5] studied the short term creep properties and microstructural changes associated with creep of a modified 9Cr-1Mo steel at 823,873 and $923 \mathrm{~K}$. Chen et al. [6] pointed out that the contribution of the static recovery of subgrains to creep deformation causes the breakdown of creep strength in Gr. 91 steel. Kim et al. [7] predicted the long-term creep life of Gr.91 steel by Larson-Miller parameter based on the collected creep rupture data through literature surveys. Ghassemo-Armaki et al. [8] studied the creep rupture life and microstructural degradation in two heats of Gr.91 steels and evaluated the coarsening of subgrains and precipitates, mainly $\mathrm{M}_{23} \mathrm{C}_{6}$ and $\mathrm{MX}$, during static aging (head portion of crept sample) and creep (gauge portion of crept sample).

Creep deformation behaviors of Grade 91 steel used for steam cooler were investigated in this paper. Uniaxial creep tests were conducted at stresses of 200, 215, 225 and $250 \mathrm{MPa}$ at $838 \mathrm{~K}$. Norton's power law, Monk man-Grant (MG) relation and modified Monk man-Grant (MMG) relation are used to analyze the creep data.

\section{Material and experimental}

The chemical composition of the studied Grade 91 steel is given in Table 1 . The hot rolled Grade 91 plate was obtained in normalized and tempered condition. The creep tests specimens were machined from the plate with a gauge length of $100 \mathrm{~mm}$ and diameter of $10 \mathrm{~mm}$, as shown in Fig. 1. Uniaxial creep tests were conducted at $200,215,225$ and $250 \mathrm{MPa}$ at $838 \mathrm{~K}$ by GWT2504 high temperature creep and stress-rupture testing machines. The creep experiments refer to GB/T2039-2002 Metallic material-creep and stress-rupture test in tension. 
Table 1 Chemical composition of Grade 91 steel (wt.\%).

\begin{tabular}{|c|c|c|c|c|c|c|c|c|c|c|}
\hline Element & $\mathrm{C}$ & $\mathrm{Mn}$ & $\mathrm{Si}$ & $\mathrm{Ni}$ & $\mathrm{Cr}$ & Mo & $\mathrm{Cu}$ & $\mathrm{Al}$ & $\mathrm{S}$ & $\mathrm{P}$ \\
\hline Amount (wt.\%) & 0.10 & 0.40 & 0.23 & 0.13 & 8.34 & 0.98 & 0.06 & 0.009 & 0.002 & 0.0101 \\
\hline & & Eleme & & V & $\mathrm{Nb}$ & $\mathrm{Ti}$ & N/Al & & & \\
\hline
\end{tabular}

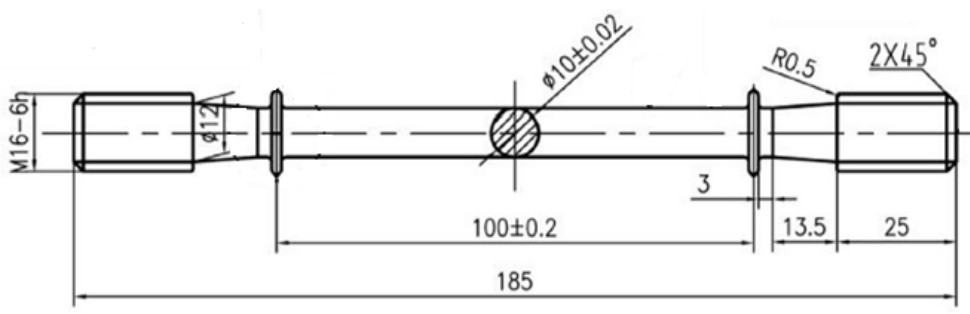

Fig. 1 Uniaxial creep test specimen.

\section{Results and Discussion}

Creep strain-time curves of Grade 91 steel at 200, 215, 225 and 250MPa at 838K are shown in Fig. 2. The curves exhibit typical primary, steady-state and tertiary creep stages under various stresses. During the steady-state stage, the occurrence of minimum creep rate results from a balance between hardening and recovery processes dominant in the primary and tertiary creep regimes, respectively. The creep strain in the tertiary creep stage accumulated more rapidly than in the primary and steady-state creep stages, which is a result of necking prior to fracture.

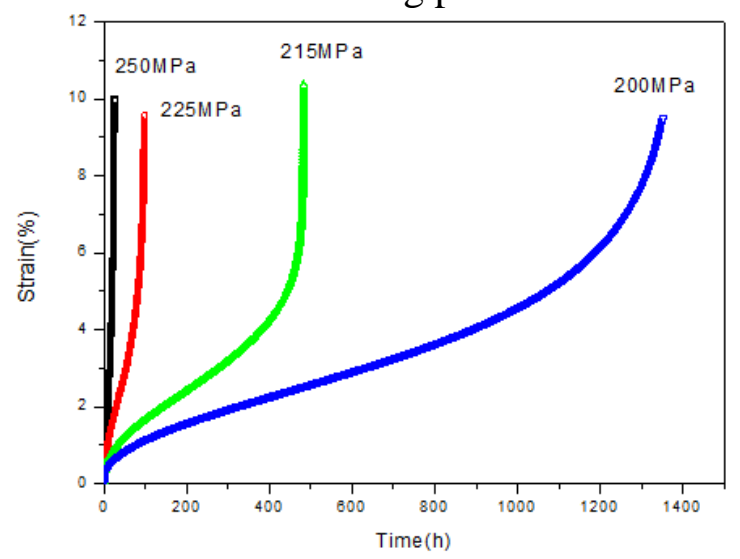

Fig. 2 Creep strain-time plots for Grade 91 steel at 838k.

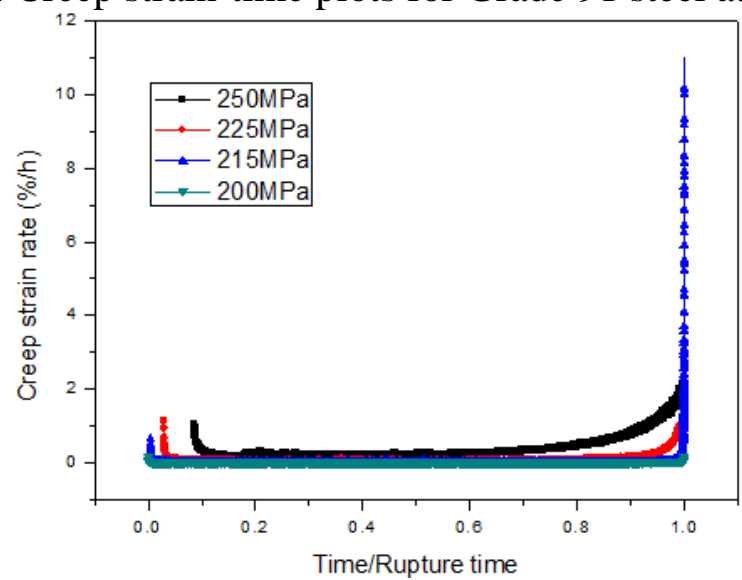

Fig. 3 Creep strain rate obtained with different stresses for Grade 91 steel at 838k.

The creep strain rate obtained with different stresses for Grade 91 steel at $838 \mathrm{~K}$ is shown in Fig. 3 . It can be seen that the steady-state stage occupies most of the creep rupture life.

The stress dependence of minimum creep rate $\dot{\varepsilon}_{\mathrm{m}}$ obeyed Norton's power law [9]:

$$
\dot{\varepsilon}_{\mathrm{m}}=A \sigma^{n}
$$


Where $A$ is the stress coefficient and $n$ is the stress exponent. The relationship between the minimum creep rate and applied stress at $838 \mathrm{~K}$ for Grade 91 steel as double logarithmic plots is shown in Fig. 4(a). It can be seen that the minimum creep rate increases with the increase of applied stress. The values of $A$ and $n$ for Grade 91 steel at $838 \mathrm{~K}$ are $2.41 \times 10^{-51}$ and 20.02 , respectively.
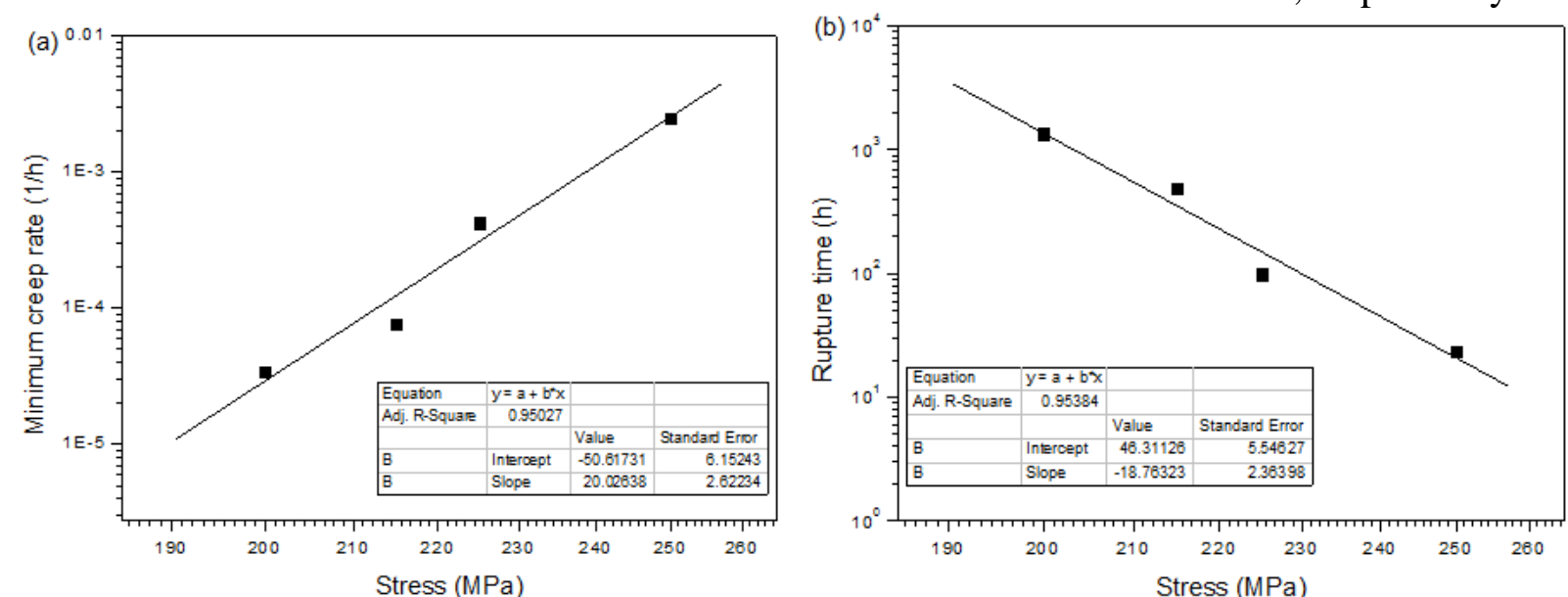

Fig. 4 Stress dependence of minimum creep rate and rupture time for Grade 91 steel at 838k.

The relationship between the creep rupture time and applied stress at constant temperature is as follows:

$$
t_{r}=B \sigma^{-v}
$$

Where $t_{r}$ is the rupture time, $B$ is the stress coefficient and $v$ is the stress exponent. The relationship of rupture time and applied stress as double logarithmic plots is shown in Fig. 4(b). It can be seen that the rupture time decreases with the increase of applied stress. The values of $B$ and $v$ for Grade 91 steel at $838 \mathrm{~K}$ are $2.05 \times 10^{46}$ and 18.76 , respectively.

The relationship between minimum creep rate in the steady-state region and creep rupture time for different stresses at $838 \mathrm{~K}$ is analyzed by Monk man-Grant Relation(MGR), which is expressed as follows [10]:

$$
\dot{\varepsilon}_{m} t_{r}=C_{M G}
$$

Where $C_{M G}$ is the Monk man-Grant constant. The validity of Monk man-Grant Relation is shown in Fig. 5. The value of Monk man-Grant constant $C_{M G}$ is 0.08 . Its value is independent of the creep test temperature and stress. Based on the short-term creep test results, some researchers estimate the long-term creep rupture life using Eq. (3).

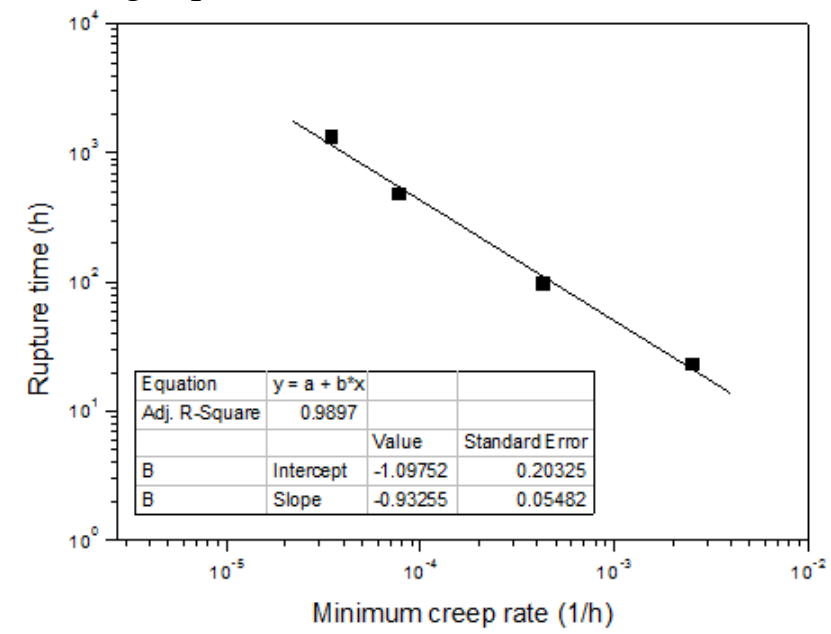

Fig. 5 Rupture time vs. minimum creep rate plot for Grade 91 steel.

The Modified Monk man-Grant (MMG) relation is also used to analyze the relationship between the minimum creep rates and rupture time, which is expressed as follows: 


$$
\dot{\varepsilon}_{m} \frac{t_{r}}{\varepsilon_{r}}=C_{M M G}
$$

Where $\varepsilon_{r}$ the strain to failure and CMMG is is the Modified Monk man-Grant constant, which is also independent of the creep test temperature and stress. The validity of Modified Monk man-Grant Relation is shown in Fig. 6. The value of Modified Monk man-Grant constant $C_{M M G}$ is 0.78 . The value of creep damage tolerance factor $\lambda$ for identifying creep rupture mode is given by inverse of $C_{M M G}$ [11].

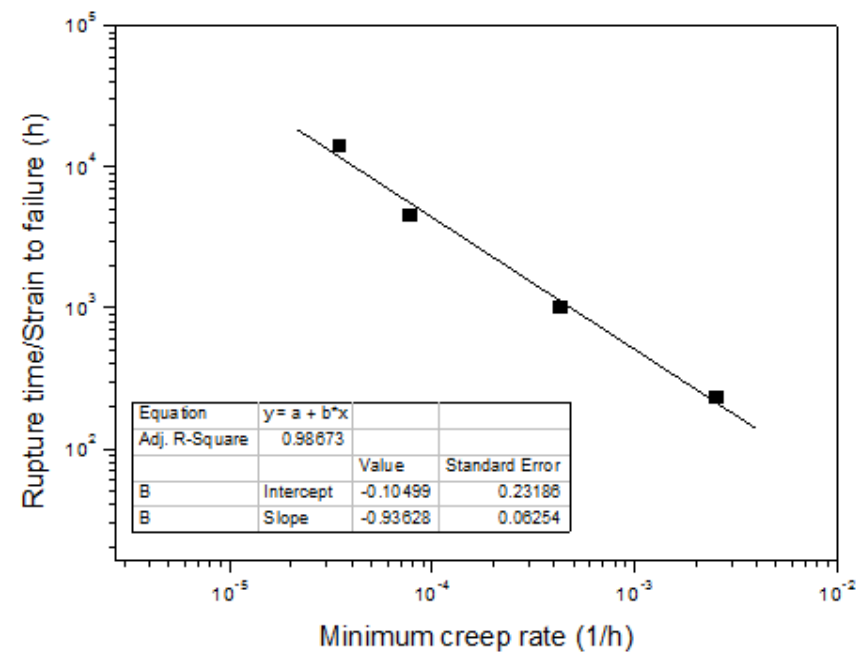

Fig. 6 Rupture time/strain to failure vs. minimum creep rate plot for Grade 91 steel.

\section{Conclusion}

Creep deformation behavior of Grade 91 steel was investigated at $838 \mathrm{~K}$ under various stresses. The stress dependence of minimum creep rate and rupture time obeyed the power law. The relationship between the minimum creep rate and rupture time obeyed the Monk man-Grant Relation and Modified Monk man-Grant Relation.

\section{Acknowledgements}

The authors gratefully acknowledge the financial supports by Shanghai Municipal Bureau of Quality and Technical Supervision (No. 2016-40).

\section{References}

[1] P.J. Ennis, A. Czyrska-Filemonowicz, Recent advances in creep-resistant steels for power plant applications, Sadhana 28 (2003)709-730.

[2] Fujio Abe, Precipitate design for creep strengthening of $9 \% \mathrm{Cr}$ tempered martensitic steel for ultra-supercritical power plants, Sci. Technol. Adv. Mater. 9 (2008) 1-15.

[3] T. Shrestha, M. Basirat, I. Charit, G.P. Potirniche, K.K. Rink, U. Shaym, Creep deformation mechanisms in modified 9Cr-1Mo steel, J. Nucl. Mater. 423 (2012) 110-119.

[4] Y. X. Chen, W. Yan, W. Wang, Y.Y.Shan, K. Yang, Constitutive equations of the minimum creep rate for 9\% Cr heat resistant steels, Mater. Sci. Eng. A. 534 (2012) 649-653.

[5] P. Anderson, T. Bellgardt, F. L. Jones, Creep deformation in a modified 9Cr-1Mo steel, Mater. Sci. Technol. 19 (2003) 207-213.

[6] R.P. Chen, H. Ghassemi Armaki, K. Maruyama, M. Igarashi, Long-term microstructural degradation and creep strength in Gr.91 steel, Mater. Sci. Eng. A. 528 (2011) 4390-4694. 
[7] W.G. Kim, J.Y. Park, S.J. Kim, J. Jang, Reliability assessment of creep rupture life for Gr.91 steel, Mater. Des. 51 (2013) 1045-1051.

[8] H. Ghassemo-Armaki, R.P. Chen, K. Mauyama, M. Igarashi, Contribution of recovery mechanisms of microstructure during long-term creep of Gr.91 steels, J. Nucl. Mater. 433 (2013) 23-29.

[9] B.K. Choudhary, E.I. Samuel, Creep behaviour of modified 9Cr-1Mo ferritic steel, J. Nucl. Mater. 412 (2011) 82-89.

[10] Y.P. Zhao, J.M. Gong, J. Yong, X.W. Wang, L.M. Shen, Q.N. Li, Creep behaviours of $\mathrm{Cr} 25 \mathrm{Ni} 35 \mathrm{Nb}$ and $\mathrm{Cr} 35 \mathrm{Ni} 45 \mathrm{Nb}$ alloys predicted by modified theta method, Mater. Sci. Eng. A. 649 (2016) $1-8$.

[11] [K. Guguloth, N. Roy, Creep deformation behavior of 9Cr1MoVNb (ASME Grade 91) steel, Mater. Sci. Eng. A. 680 (2017) 388-404. 